\title{
BACTERIOLOGICAL AND MOLECULAR CHARACTERIZATION OF DIARRHEAGENIC ESCHERICHIA COLI PATHOTYPES FROM CHILDREN IN DUHOK CITY, IRAQ
}

\author{
Haveen K. Hasan ${ }^{\text {a }}$,Najim A. Yassin ${ }^{\mathrm{b}}{ }^{*}$, Souzan H. Eassa ${ }^{\mathrm{c}}$ \\ a Technical Institute, Duhok Polytechnic University, Duhok, Iraq-(haveenbio@gmail.com) \\ b Dept. Of Medical Microbiology, College of Medicine, Duhok University, Kurdistan Region, Iraq- (najim56@yahoo.com) \\ ${ }^{c}$ Dept. of Histology and Medical Biology, College of Medicine, Duhok University, Kurdistan Region - Iraq \\ (souzan.eassa@uod.ac)
}

Received: Feb., 2020 / Accepted: Apr., 2020 / Published: Jun.,2020

https://doi.org/10.25271/sjuoz.2020.8.2.702

\begin{abstract}
:
Background: A variety of diarrheagenic $E$ coli (DEC) are responsible for causing different types of diarrhea in children especially in developing courtiers.

Objectives: This study was primarily aimed to isolate and bacteriological characterizing of $E$ coli from diarrheic infant stool and to investigate their antibiotic resistance patterns and then using molecular identification of DEC pathotypes for better discrimination.

Methods: Total of 400 fresh stools specimens were collected from children with diarrhea in Heevi Hospital in Duhok city, Iraq. The samples were cultured on selective media such as (MacConkey and MacConkey sorbitol agar). Colonies were identified through biochemical reaction and VITEK 2 system and then antibiotic susceptibility profiles were determined.

Results: A total of 349(87.2\%) samples were yielded positive for growth of $E$ coli. Out of these, 50 phenotypically-identified $E$ coli were then subjected to PCR assay targeting certain virulence factors (alt, eae, sxt 1 and $s x t 2)$ for discrimination of pathotyes. 13/50(26\%) Enterotoxigenix E. coli (ETEC) was detected, 5/50(10\%) Enterohemorrhagic E coli EHEC was detected, while no Enteropathogenic $E$ coli (EPEC) was detected. All pathotypes were more frequent in samples from male children aged between $2-$ 3 years that were artificial feeding pattern. Moreover, all pathotypes expressed high resistant to ampicillin, cephalosporin and tetracycline while little resistance to imipenem was observed. Conclusion: The study concludes presence of diarrheagenic $E$ coli pathotypes in our community causing diarrhea in children and emphasize on using of PCR assay for best discrimination.
\end{abstract}

KEYWORDS: Diarrheagenic Escherichia coli, Stool, MacConkey-Sorbitol agar, Virulence factors, PCR.

\section{INTRODUCTION}

A variety of recognized microorganisms can be associated with diarrhea in children, including: bacteria and parasites. Several studies have stated that, among bacterial pathogens associated with diarrhea in developing countries, the diarrheagenic Escherichia coli (DEC) strains are the most bacterial pathogens worldwide (Canizalez et al, 2016; Spano et al., 2017). In fact, the frequencies of these DEC differ with geographic region and according to the socioeconomic/sanitary conditions achieved (Black et al., 2010).

Escherichia coli are, in fact, an important member of the normal human intestinal microflora, but some of their strains having developed abilities to cause diseases in the human host: such as in gastrointestinal, urinary, and nerves system (Canizalez et al, 2016). It has been observed that, E. coli is one of the common causative agents of diarrheal over the world (Nguyen et al., 2005). However, based on specific virulence factors, and phenotypic traits, there are 6 pathotypes of diarrheagenic strains of $E$. coli including: enteropathogenic E. coli (EPEC), enterotoxigenic $E$. coli (ETEC), Vero toxin-producing/Shiga toxin-producing E. coli (VTEC/STEC) which include its well-known subgroup enterohaemorrhagic E. coli (EHEC), enteroinvasive E. coli
(EIEC), enteroaggregative E. coli (EAEC), and diffusely adherent $E$. coli (DAEC) (Kaper et al., 2004).

In order to identify diarrheagenic E. coli, bacteriological characterization are necessary to be performed routinely in all diagnostic laboratories, including: stool cultures in order to isolate E. coli, and biochemical test. MacConkey-sorbitol agar is selective and differential medium for presumptive isolation of enterohaemorrhagic E. coli (EHEC) pathotype that fails to ferment sorbitol sugar and gave colorless colonies. Some of the suspected E. coli was subjected to automated system susceptibility testing, i.e. bacterial identification system (wellknown as VITEC 2 system). However, unfortunately, bacteriological examination and characterization methods are not enough. In other words, these methods cannot be performed alone, since pathogenic $E$. coli cannot be distinguished from the non-pathogenic $E$ coli which, in turns, can be found normally in human feces (Spano et al., 2017). Therefore, the discrimination of diarrheagenic $E$ coli strains requires molecular techniques based on DNA target screening for isolates harboring virulence genes.

Polymerase Chain Reaction (PCR) is a major develop in molecular diagnostics of pathogenic microorganisms including $E$ coli, which has a great sensitivity and high specificity in detection of target templates over classical bacteriological methods (Fujioka et al., 2013). No molecular methods applied for detection and discrimination of diarrheagenic $E$ coli pathotypes

* Corresponding author

This is an open access under a CC BY-NC-SA 4.0 license (https://creativecommons.org/licenses/by-nc-sa/4.0/) 
in screened diarrheal stools sample in children in Duhok city, Kurdistan region, Iraq. In order to detect these categories of $E$. coli strains, it is necessary to perform several PCRs with different primers specific for these genes. Therefore, in this work we used a rapid and reliable diagnosis of human diarrheagenic E. coli pathotypes by PCRs with different primer pairs targeting virulence genes.

\section{PATIENTS AND METHODS}

\subsection{Clinical specimens}

This study was conducted in Heevi Hospital, Duhok city, Kurdistan region, in northern of Iraq. The period that has been devoted was carried out from May 2018 to April 2019. In this cross-sectional study, a total of 400 diarrheic stool samples were collected from children aged (1-5) years $(238$ male and 162 female) that suffered from diarrhea. As well as, nutritional status of children whether breast (285) or bottle (115) feeding was recorded in this study. The study excluded those children who had used antibiotic drugs before admission.

\subsection{Ethical consideration}

Study proposal and informed consent was approved by ethics committee of the college of Medicine, Duhok University and Duhok Public Health Directorate, Kurdistan Region, Iraq. From all patients, formal consent was taken from their parents/guardians before collecting the samples.

\subsection{Sample collection and processing}

Fresh stool samples were collected from each child and put in an appropriate place, clean, wide-mouth container. The macroscopic examination of fresh stool was performed such as consistency (formed, soft, watery, liquid, and mucoid), colour (brown, yellow, green, black, and red), blood (not seen, few, moderate, present, and abundant), mucus (not seen, few, moderate, present, and abundant).

A loopful from fresh watery and mucoid stools samples were streaked on Blood agar, MacConkey agar, while, bloody stools samples were streaked on MacConkey-sorbitol agar. Both sets of media were incubated for $18-24$ hours at $37^{\circ} \mathrm{C}$. Three lactose-fermenting purified colonies and a corresponding representative non-lactose fermenting colonies from MacConkey agar and MacConkey-sorbitol agar were picked, respectively for phenotypic identities using a classical biochemical tests (Engelkirk \& Duben-Engelkirk, 2008) and then subjected to VITEK 2 automated system for the identification of bacterial species (Versalovic et al.,
2011). Confirmed E. coli isolates were stored at $-20^{\circ} \mathrm{C}$ in Trypticase soy broth supplemented with $20 \%$ glycerol for further procedures (Cheesbrough, 2006).

\subsection{Antimicrobial susceptibility test}

All $E$ coli isolates were tested for antibiotic susceptibility assay according to Kirby-Bauer disc diffusion technique (Bauer et al., 1966) as per the recommendation of Clinical and Laboratory Standards Institute (CLSI) (Weinstein et al., 2017). Antibiotics panels have been used as a guide to testing the sensitivity of bacteria to the 13 antibiotics (Oxoid) including the following: cefotaxime $(30 \mu \mathrm{g})$, amikacin $(10 \mu \mathrm{g})$, ceftriaxone $(10 \mu \mathrm{g})$, cefixime $(5 \mu \mathrm{g})$, tetracycline $(30 \mu \mathrm{g})$, gentamicin $(10 \mu \mathrm{g})$, ciprofloxacin $(10 \mu \mathrm{g})$, imipenem(10 $\mu \mathrm{g})$, amoxicillin $(20 \mu \mathrm{g})$, chloramphenicol $(10 \mu \mathrm{g})$, amoxicillin/ clavulanic acid $(20 / 10 \mu \mathrm{g})$, trimethoprim/ sulphamethoxazole $(10 / 50 \mu \mathrm{g})$ and ampicillin $(20$ $\mu \mathrm{g})$. Briefly, an overnight suspension broth culture that matched to 0.5 MacFarland Standard were uniformly inoculated by a cotton swab on Muller-Hinton agar then incubated at $37{ }^{\circ} \mathrm{C}$ for 24 hours. Plates were then read by measurement of the zones of growth inhibition (millimetre) around each of the antibiotic disks. The zone diameters of drugs were interpreted based on Clinical and Laboratory Standards Institute criteria (noted as CLSI) (Weinstein et al., 2007).

\subsection{DNA Extraction}

For the molecular characterization and PCR assay, 50 isolates of $E$ coli were choice according to their cultural characteristics on MacConkey agar and MacConkey -Sorbitol- agar. Out of these 35 isolates were taken from MacConkey agar and another 15 were from MacConkey -Sorbitol- agar.

The extraction of DNA was performed from the sweep of a few colonies of bacteria that were grown on blood- Agar plates utilizing boiling method (Liu, 2011). The extraction of crude genomic DNA was performed by heating samples for 20 minutes at $120{ }^{\circ} \mathrm{C}$ and high-speed centrifugation $(3500 \mathrm{rpm}$ for 20 minutes) for 15 minutes. Supernatants were then used as DNA template for PCR. Determination of DNA concentration and purity of each isolate was determined using Nano-drop spectrometer (Cambridge, England) instrument.

\subsection{PCR Amplification protocol}

Monoplex PCR for categorization of E. coli into ETEC, EHEC and EPEC was performed using; published primers (Fujioka et $a l ., 2013)$ as in Table (1) for identification of virulence genes elt and eae, respectively. On the other hand, multiplex PCR was applied for assign of EHEC using specific primers for detection of $s t x 1$ and $s t x 2$, as seen in Table (1).

Table 1. Specific genes, primers sequences and expected products for PCR assays used for various virulence genes among diarrheagenic $E$ coli.

\begin{tabular}{|c|c|c|c|}
\hline Pathotype & Specific gene & Primers $\left(5^{\prime} \rightarrow 3^{\prime}\right)$ & $\begin{array}{c}\text { Product } \\
\text { size }(\mathrm{bp})\end{array}$ \\
\hline \multirow{2}{*}{ EPEC } & $e a e$ & $\begin{array}{r}\text { F:CCCGAATTCGGCACAAGCATAAGC } \\
\text { R:CCGGATCCGTCTCGCCAGTATTCG }\end{array}$ & 881 \\
\hline \multirow{2}{*}{ EHEC } & stx 1 & $\begin{array}{l}\text { F:AACGTTCCGGAGGTCTTATG } \\
\text { R:CAACCTTGTGGTGCATGATG }\end{array}$ & 511 \\
\cline { 2 - 4 } & $s t x 2$ & $\begin{array}{r}\text { F:AGTTAATGTGGTGGCGAAGG } \\
\text { R:CACCAGACAATGTAACCGC }\end{array}$ & 347 \\
\hline R:CGTCATCGTATACACAGGAG & 589 \\
\hline
\end{tabular}

$\mathrm{EPEC}=$ enteropathogenic $E$. coli $;$ ETEC = enterotoxigenic $E$. coli; $\mathrm{EHEC}=$ enterohemorrhagic $E$. coli. Note that: $\mathrm{F}=$ forward; $\mathrm{R}=$ reverse 
The master mix of PCR reaction was performed in final reaction of a total volume of $25 \mu \mathrm{L}$. Each reaction contained $2 \mu \mathrm{L}$ of primer( $10 \mathrm{pmol} \mu \mathrm{l}-1)$ mixture $(1 \mu \mathrm{L}$ for each forward and reverse primer), $1 \mu \mathrm{L}$ of DNA template $(25 \mathrm{ng} / \mathrm{ml}), 10$ $\mu \mathrm{L}$ of Master Mix and $12 \mu \mathrm{L}$ of Nuclease free water. PCR amplification was performed for the following thermal and cycling condition (Toma et al., 2003) : initial denaturation at $95^{\circ} \mathrm{C}$ for $3 \mathrm{~min}$, followed by 30 cycles of denaturation at $94^{\circ} \mathrm{C}$ for $1 \mathrm{~min}$, annealing at $56^{\circ} \mathrm{C}$ for $1 \mathrm{~min}$, and extension at $72^{\circ} \mathrm{C}$ for $1 \mathrm{~min}$; and final extension at $72^{\circ} \mathrm{C}$ for $5 \mathrm{~min}$. The PCR products were then separated in $1.5 \%$ agarose gel to detect specific amplified product by comparing with standard molecular weight marker.

\subsection{Statistical Analysis:}

Statistical analysis was carried out using Stata 16 program. The significant difference between variables was determined using Fisher and Chi square test (Sokal and Rohlf, 2013). P value $<0.05$ was considered a significant.

\section{RESULTS}

Out of 400 fresh stool samples that cultivated on MacConkey and Sorbitol- MacConkey agar, 349 (87.2\%) isolates were yielded positive growth that distributed between 298 isolates with pink lactose fermentative colonies on MacConkey agar and other 51 isolates with non-sorbitol fermentative colonies on Sorbitol- MacConkey agar that was presumptively identified as a pathotype Enterohemorrhagic E. coli. Watery, mucoid and soft stool samples largely yielded positive growth of $E$ coli on MacConkey agar, while majority of bloody stool samples were appeared non sorbitol fermenter colonies on Sorbitol- MacConkey agar. All recovered isolates from both media were further subjected to Vitek 2 system for definitive confirmation and identification that was $91.3 \%$ similarity of characteristics of $E$ coli.

Table (2), show percentages of overall $E$ coli isolated from diarrheic stool samples from children aged between 1-5 years, the percentage of infections was slightly higher in male $(87.4 \%)$ gender than female $(87.0 \%)$ but statistically was not significant $(p<0.71)$. Furthermore, the highest infection rates were found among children aged between 2-3 years $(95.3 \%)$ and the lowest rate were seen in age between 4-5 years of age and statistically was not significant $(\mathrm{p}<0.162)$. According to feeding status, the highest recovery of $E$ coli rate was seen with artificial feeding $(89.5 \%)$ and also no significant difference was found between them $(\mathrm{p}<0.7)$.

Generally, the highest resistance rate of antibiotics was noticed against amoxicillin (100\%), followed by ampicillin (98.6\%), amoxicillin/ clavulanic acid $(97.2 \%)$, tetracycline $(98.6 \%)$, while moderate resistance was recorded against chloramphenicol and ciprofloxacin. The lowest resistance was with imipenem with $10 \%$, and $6.7 \%$ for both isolates from MacConkey agar and MacConkey -Sorbitol agar, respectively (Table 3).

Table 2. Percentages of $E$ coli isolated from total examined diarrheic stool samples among genders, age groups and feeding status

\begin{tabular}{|c|c|c|c|c|}
\hline \multirow{2}{*}{ Variables } & \multicolumn{4}{|c|}{ Prevalence of $E$ coli infections by culture } \\
\cline { 2 - 4 } & $\begin{array}{c}\text { Positive } \\
\text { No. (\%) }\end{array}$ & $\begin{array}{c}\text { Negative } \\
\text { No. (\%) }\end{array}$ & Total & $\begin{array}{c}* \text { *P } \\
\text { Value }\end{array}$ \\
\hline Gender & & & & \multirow{2}{*}{0.710} \\
\hline Male & $208(87.4)$ & $30(12.6)$ & 238 & \\
\hline female & $141(87.0)$ & $21(13)$ & 162 & \\
\hline Age & \multicolumn{4}{|c|}{} \\
\hline$>1$ year & $163(85.8)$ & $27(14.2)$ & 190 & \\
\hline
\end{tabular}

\begin{tabular}{|c|c|c|c|c|}
\hline 1-2 years & $87(86.1)$ & $14(13.9)$ & 101 & \multirow{2}{*}{0.162} \\
\cline { 1 - 4 } 2-3 years & $41(95.3)$ & $2(4.7)$ & 43 & \\
\hline 3-4 years & $35(94.6)$ & $2(5.4)$ & 37 & \\
\hline 4-5 years & $23(79.3)$ & $6(20.7)$ & 29 & \\
\cline { 1 - 4 } Feeding & \multicolumn{3}{|l}{} \\
\cline { 1 - 4 } Breast & $94(81.7)$ & $21(18.3)$ & 115 & \multirow{2}{*}{0.7} \\
\cline { 1 - 3 } Bottle & $255(89.5)$ & $30(10.5)$ & 285 & \\
\hline
\end{tabular}

*The data was statistically analysed using Chi-Square test (or Fisher exact test). $P$ values $<0.05$ were considered as a significant.

Table 3. Patterns of antibiotic-susceptibility test of all phenotypically $E$ coli isolates grown on MacConkey and Sorbitol- MacConkey agar.

\begin{tabular}{|c|c|c|}
\hline Antibiotics & $\begin{array}{c}\text { Resistance Rates } \\
\text { (MacConkey } \\
\text { agar) \% }\end{array}$ & $\begin{array}{c}\text { Resistance Rates } \\
\text { (MacConkey- } \\
\text { Sorbitol agar) \% }\end{array}$ \\
\hline $\begin{array}{c}\text { Trimethoprim/ } \\
\text { Sulphamethoxazole (SXT) }\end{array}$ & 77.1 & 86.7 \\
\hline Imipenem (IPM) & 10 & 6.7 \\
\hline Ampicillin (AM) & 98.6 & 96.7 \\
\hline Amoxicillin (AX) & 100 & 100 \\
\hline Chloramphenicol (C) & 51.4 & 33.3 \\
\hline Cefotaxime (CTX) & 85.7 & 86.7 \\
\hline Tetracycline (TE) & 98.6 & 100 \\
\hline Ciprofloxacin (CIP) & 42.9 & 33.3 \\
\hline Ceftriaxone (CRO) & 87.1 & 90 \\
\hline Gentamicin (CN) & 82.9 & 70 \\
\hline Amikacin (AK) & 85.7 & 93.3 \\
\hline Amoxicillin/clavulanic acid & 97.1 & 96.7 \\
\hline (AMC) & 92.9 & 90 \\
\hline Cefixime (CFM) & (AM) & \\
\hline
\end{tabular}

It was found that out of 35 isolates of lactose-fermenter growth on MacConkey agar that subjected to PCR assay by using specific primer of elt and eae virulence genes, 13 of them successfully produced amplified products $(511 \mathrm{bp})$ with elt and no isolate was contained eae (Figure 1) and (Figure 2), respectively. Five out of fifteen isolates on MacConkey-Sorbitol agar amplified only stxl gene and no stx2 gene as it is shown in Table (4) and in Figure (3).

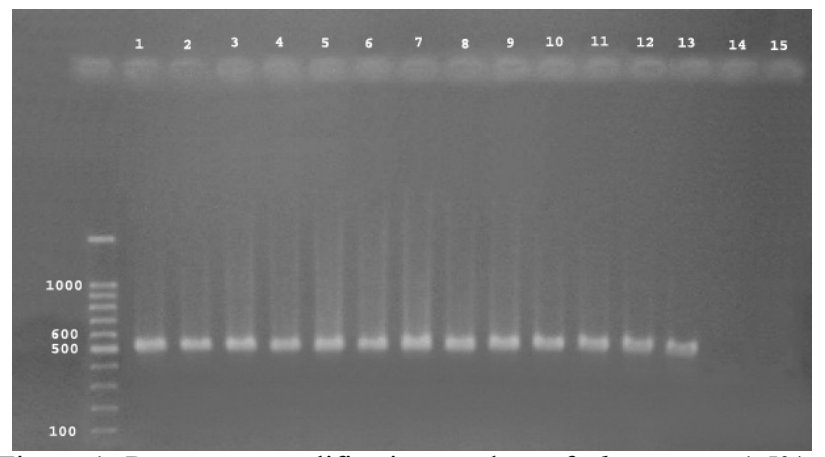

Figure 1. Represent amplification product of elt gene on $1.5 \%$ agarose gel, ladder $100 \mathrm{bp}$, lanes (1 to 13) isolates produced amplified products $(511 \mathrm{bp})$; lanes 14 and 15 not produced amplified products. 


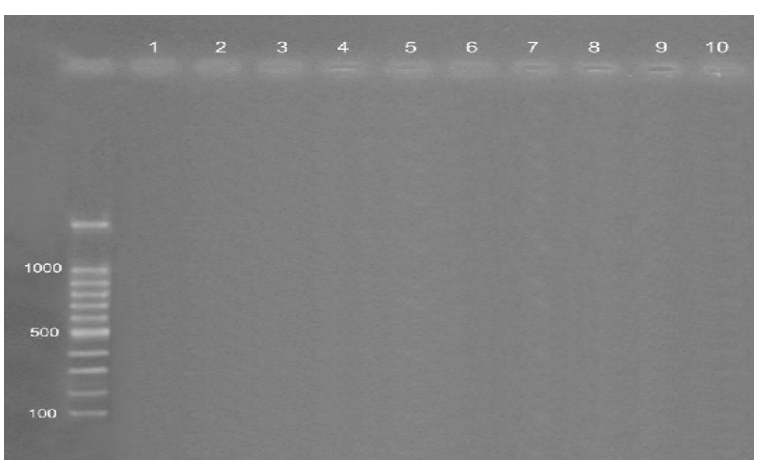

Figure 2. Represent no amplification product of eae gene on $1.5 \%$ agarose gel, ladder $100 \mathrm{bp}$, lanes from 1 to 10 not produced amplified products ( $881 \mathrm{bp})$.

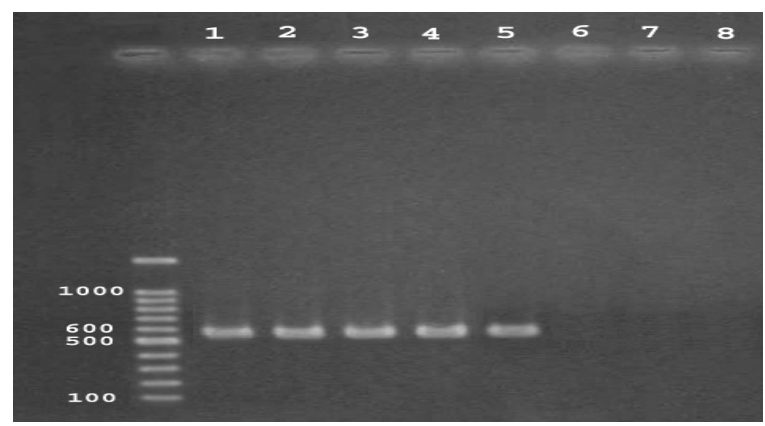

Figure 3. Represent amplification product of stxl and stx2 genes on $1.5 \%$ agarose gel, ladder $100 \mathrm{bp}, 5$ lanes (1 to 5 ) isolates produced amplified products (589 bp) with $s t x 1$; and no amplified products produced with stx 2 .

Table 4. PCR assay targeting various virulence genes of three pathotypes of diarrheagenic $E$ coli

\begin{tabular}{|c|c|c|c|}
\hline \multirow{2}{*}{ Results } & \multicolumn{2}{|c|}{$\begin{array}{c}35 \text { sample on MacConkey } \\
\text { agar }\end{array}$} & $\begin{array}{c}15 \text { sample on } \\
\text { MaConkey-Sorbitol } \\
\text { agar }\end{array}$ \\
\hline & $\begin{array}{c}\text { ETEC } \\
\text { elt } \text { amplified } \\
\text { gene }\end{array}$ & $\begin{array}{c}\text { EPEC } \\
\text { eae amplified } \\
\text { gene }\end{array}$ & $\begin{array}{c}\text { EHEC } \\
\text { stx } 1 \text { and stx3 } \\
\text { amplified genes }\end{array}$ \\
\hline$+\mathrm{ve}$ & $13(37 \%)$ & $0(0 \%)$ & $5(33 \%)$ \\
\hline$-v e$ & $22(63 \%)$ & $35(100 \%)$ & $10(67 \%)$ \\
\hline
\end{tabular}

Furthermore, Table (6) shows the results of antibiotic susceptibility test for those $E$ coli pathotypes that were identified by PCR. The highest resistance rate of Enterotoxigenic E. coli $(100 \%)$ was still found for amoxicillin, ampicillin, cefotaxime and tetracycline and the lowest rate of resistance to imipenem (15\%). For the Enterohaemorrhagic pathotypes, the highest rate of resistance $(100 \%)$ was seen for amoxicillin, sulfamethoaxazoal, tetracycline and amikacin. Meanwhile, no resistance rate was seen with imipenem in any of the patients $(0 \%)$ (Table 5).
Table 5. Antibiotic susceptibility patterns of molecularlyidentified pathotypes of diarrheagenic $E$. coli

\begin{tabular}{|c|c|c|}
\hline Antibiotics & $\begin{array}{c}\text { ETEC } \\
(13 \text { isolate })(\%)\end{array}$ & $\begin{array}{c}\text { EHEC } \\
(5 \text { isolates }) \\
(\%)\end{array}$ \\
\hline $\begin{array}{c}\text { Trimethoprim/ } \\
\text { Sulphamethoxazole (SXT) }\end{array}$ & $12(92)$ & $5(100)$ \\
\hline Imipenem (IPM) & $2(15)$ & $0(0)$ \\
\hline Ampicillin (AM) & $13(100)$ & $4(80)$ \\
\hline Amoxicillin (AX) & $13(100)$ & $5(100)$ \\
\hline Chloramphenicol (C) & $7(53)$ & $3(60)$ \\
\hline Cefotaxime (CTX) & $13(100)$ & $3(60)$ \\
\hline Tetracycline (TE) & $13(100)$ & $5(100)$ \\
\hline Ciprofloxacin (CIP) & $9(69)$ & $2(40)$ \\
\hline Ceftriaxone (CRO) & $13(100)$ & $4(80)$ \\
\hline Gentamicin (CN) & $9(69)$ & $3(60)$ \\
\hline Amikacin (AK) & $10(76)$ & $5(100)$ \\
\hline Amoxicillin/Clavulanic acid & $13(100)$ & $4(80)$ \\
\hline (AMC) & $12(92)$ & $4(80)$ \\
\hline Cefixime (CFM) & &
\end{tabular}

\section{DISCUSSION}

Diarrheagenic Escherichia coli pathotypes are commonly involved in diarrheal disease in children in our setting due to factors of contamination. To our knowledge, no study has been performed in line of molecular identification of causes of diarrhea, especially diarrheagenic Escherichia coli pathotypes among children equal or less than five years of age in Duhok City, Kurdistan region, Iraq. Therefore, the current study was implanted phonotypical and molecular methods to identify these pathotypes among children equal or less than five years of age in studies region In this study, overall 349(87.2\%) of diarrheic stool samples were showed positive culture characteristics of $E$ coli on both MacConkey and MacConkey-sorbitol- agar. In the present study, $E$ coli were more frequently isolated in male than female and the highest infection rates were also found in age between 23 years old. In terms of feeding, the highest $E$ coli infection rate was recorded in artificial feeding than breast feeding.

Furthermore, the isolates of $E$ coli were showed high resistant to old antibiotics such as ampicillin, cephalosporin and tetracycline but lowest resistance was seen to imipenem. Similar findings have been reported in Zakho city, Kurdistan Region, Iraq, by Badry et al. (2014) where $E$ coli is the most prevalent enteric pathogen which was $(58.43 \%)$. Similar findings were also reported in other studies (McAuliffe et al., 2013; Rashedul, 2011). In another study conducted in Libya, it has found diarrheagenic $E \mathrm{col}$ was the most common detected bacterial pathogens (Rahouma et al., 2011). These high rates of recovery of $E$ coli found in the current study may be due to low education of parents, low-grade of health hygiene, poor toilet training, lack of exclusive breastfeeding, artificial feeding, source of water supply, overcrowding and climatic conditions (Hellard et al., 2000).

Generally, E coli are the predominant nonpathogenic member of the human intestinal normal flora usually isolated from stool samples (Hellard et al., 2000). This explain the highly rate of presence of $E$. coli was detected in the present study. In fact, the pathogenic strains of $E$ coli are well differentiated from the nonpathogenic by using a common molecular test such as PCR using specific primers. For this reason, in current study, 50 isolates of phenotypically-identified $E$ coli that subjected to PCR assay by using specific primers targeting virulence genes, 
Enterotoxigenix $E$ coli (ETEC) was detected in 13 samples (26\%), Enterohemorrhagic E coli EHEC 5 (10\%), while no Enteropathogenic $E$ coli (EPEC) detected. Moreover, watery and soft stools samples were mainly contained ETEC while most bloody samples confirmed harboring EHEC. In other parts of Iraq, some PCR-based studies detected $26.3 \%$, $19.2 \%$ and $21.6 \%$ of ETEC in stool samples by (Arif \& Salih, 2010; Al-Dulaimi et al., 2015; Khalil, 2015), respectively. Other studies conducted in Bangladesh, Egypt and Iran were recognized ETEC by PCR as major pathotype among children less than 5 years (Nessa et al., 2007; El Metwally et al., 2007; Haghi et al, 2014). Low-grade hygienic state of family and artificial feeding may account for this high rate of ETEC.

Enterohemorrhagic $E$ coli EHEC was found the second most prevalent detected by PCR test in this study $(33 \%)$. This finding was higher than two studies performed in Iraq using PCR assay also, one by Al-Dulaimi (2015) in TheQar/Iraq, found (5.27\%) (Al-Dulaimi et al., 2015) and other by Khalil, found $7.8 \%$ (Khalil, 2015). In Iran, Nigeria and Bangladish, the rates of infection detected by PCR were $1.4 \%, 25 \%$ and 11.7\% (Nessa et al, 2007; Sharifi A et al., 2011; Ifeanyi et al., 2015). Whereas, in Sulaimaniah/Iraq, Arif and Salih (2010) were not detected any EHEC pathotype in their study. Khabir (2011), in Bangladesh, there were no EHEC have been detected (Rashedul, 2011). The higher rates of EHEC in our study might be due to taking of contaminated waters and foods including uncooked minced ready meat at fast food restaurants as well as contaminated vegetables with animal feces, in addition to raw milk combined with low infective dose of this pathotype (Sperandio \& Pacheco, 2012).

In the current study, none of Enteropathogenic $E$ coli pathotype EPEC was detected when we used a specific primer for eae gene. Similar result was found in study conducted in Bangladesh, by Rashedul (2011) and in Egypt, by El-Metwally et al. (2007), they detected very low rate of EPEC with $3.5 \%$. This present result is in contrast to finding of study performed in Baghdad by Khalil (2015); it has detected the highest infection rate of EPEC (29.4\%) among children under 5 years old. The possibility of using more than one primer may yield positive amplification; in addition geographical differences may also effect on the prevalence of EPEC pathotype.

In current study, antibiotic susceptibility patterns for those ETEC and EHEC that molecularly identified were variable. ETEC was still expressed high resistance to commonly used antibiotics except $15 \%$ resistance to imipenem, while corresponding phenotypically isolates grown on MacConkey agar expressed $10 \%$ resistance. The current findings were accord with two studies conducted in Vietnam and India (Nguyen et al., 2005; Sudershan et al, 2014). Generally, EHEC pathotype exhibited analogue patterns of antibioticsusceptibility namely high susceptibility to imipenem. This is in accordance with studies conducted in Bangladesh (Rashedul, 2011) and Germany (Presterl et al., 2003).

\section{CONCLUSION}

The present study concludes that certain pathotypes of highly antibiotic resistant diarrheagenic $E$ coli are circulating in our setting, the study emphasize on employment of molecular tests such as multiplex PCR for discrimination of pathogenic $E$ coli from non-pathogenic $E$ coli in cases of infants diarrhea.

\section{ACKNOWLEDGEMT}

The authors are grateful to the children and their parents for kindly providing the stool samples. We thank the laboratory staff of Heevi hospitals and Duhok Central Health laboratories for their contribution in collecting the samples and performing of molecular part for study, respectively. Also our thanks extend to the Department of Microbiology, College of Medicine, Duhok University for the logistic support.

\section{REFERENCES}

Al-Dulaimi, T. H., Aziz, H. W., Al-Marzoqi, A. H., Al-Aziz, S. A., \& Mohsin, S. A. A. (2015). Molecular characterization and antibiotic susceptibility of diarrheagenic Escherichia coli from Children. Medical Journal of Babylon, 12(2), 541-550.

Arif, S. K., \& Salih, L. I. (2010). Identification of Different Categories of Diarrheagenic" Escherichia coli" in Stool Samples by Using Multiplex PCR Technique. Asian Journal of Medical Sciences, 2(5), 237-243.

Bauer, A. (1966). Antibiotic Susceptibility Testing by a standardized single disc method. Am J clin pathol, 45, 149-158.

Black, R. E., Cousens, S., Johnson, H. L., Lawn, J. E., Rudan, I., Bassani, D. G., Cibulskis, R. (2010). Global, regional, and national causes of child mortality in 2008: a systematic analysis. The lancet, $375,1969-1987$.

Canizalez., R. A., Flores-Villaseñor., H.M., Gonzalez., N. E., Velazquez., R. J, Vidal., J.E., Muro- Amador., S, et al. (2016) Surveillance of Diarrheagenic Escherichia coli Strains Isolated from Diarrhea Cases from Children, Adults and Elderly at Northwest of Mexico. Front. Microbiol. 7, 1924.

Cheesbrough, M. (2006). District laboratory practice in tropical countries: Cambridge university press.

El Metwally, H. A., Ibrahim, H. A., El-Athamna, M. N., \& Amer, M. A. (2007). Multiplex PCR for detection of diarrheagenic Escherichia coli in Egyptian children. Journal of Medical Sciences, 7(2), 255-262.

Engelkirk, P. G., \& Duben-Engelkirk, J. L. (2008). Laboratory diagnosis of infectious diseases: essentials of diagnostic microbiology: Lippincott Williams \& Wilkins.

Fujioka, M., Otomo, Y., \& Ahsan, C. R. (2013). A novel single-step multiplex polymerase chain reaction assay for the detection of diarrheagenic Escherichia coli. Journal of microbiological methods, 92(3), 289-292.

Haghi, F., Zeighami, H., Hajiahmadi, F., Khoshvaght, H., \& Bayat, M. (2014). Frequency and antimicrobial resistance of diarrhoeagenic Escherichia coli from young children in Iran. Journal of medical microbiology, 63(3), 427-432.

Hellard, M. E., Sinclair, M. I., Hogg, G. G., \& Fairley, C. K. (2000) Prevalence of enteric pathogens among community based asymptomatic individuals. Journal of gastroenterology and hepatology, 15(3), 290-293.

Ifeanyi, C. I. C., Ikeneche, N. F., Bassey, B. E., Al-Gallas, N., Aissa, R. B., \& Boudabous, A. (2015). Diarrheagenic Escherichia coli pathotypes isolated from children with diarrhea in the Federal Capital Territory Abuja, Nigeria. The Journal of Infection in Developing Countries, 9(02), 165-174.

Kaper, J. B., Nataro, J. P., Mobley, H. L. (2004). Pathogenic Escherichia coli. Nature reviews microbiology, 2(2), 123-140.

Khalil, Z. K. (2015). Isolation and identification of different diarrheagenic (DEC) Escherichia coli pathotypes from children under five years old in Baghdad. Iraqi journal of community medicine, 28(3), 126-132.

Liu, D. (2011). Molecular detection of human bacterial pathogens: 1st edition, CRC press.

McAuliffe, G. N., Anderson, T. P., Stevens, M., Adams, J., Coleman, R., Mahagamasekera, P., Jennings, L. C. (2013). Systematic application of multiplex PCR enhances the detection of bacteria, parasites, and viruses in stool samples. Journal of Infection, 67(2), 122-129.

Nessa, K., Ahmed, D., Islam, J., Kabir, F. L., \& Hossain, M. A. (2007). Usefulness of a multiplex PCR for detection of diarrheagenic Escherichia coli in a diagnostic microbiology laboratory setting. Bangladesh Journal of Medical Microbiology, 1(2), 38-42.

Nguyen, T. V., Le Van, P., Le Huy, C., Gia, K. N., Weintraub, A. (2005). Detection and characterization of diarrheagenic Escherichia coli from young children in Hanoi, Vietnam. Journal of clinical microbiology, 43(2), 755-760.

Presterl, E., Zwick, R. H., Reichmann, S., Aichelburg, A., Winkler, S., Kremsner, P. G., \& Graninger, W. (2003). Frequency and 
virulence properties of diarrheagenic Escherichia coli in children with diarrhea in Gabon. The American journal of tropical medicine and hygiene, 69 (4), 406-410.

Rahouma, A., Klena, J. D., Krema, Z., Abobker, A. A., Treesh, K., Franka, E., Abudher, A. (2011). Enteric pathogens associated with childhood diarrhea in Tripoli-Libya. The American journal of tropical medicine and hygiene, 84(6), 886-891.

Rashedul, K. (2011). Detection of Different Diarrheagenic Escherichia coli Strains by Multiplex PCR assay. Department of Microbiology (Master thesis submitted to Mymensingh Medical College, Mymensingh University), Mymensingh, Bangladesh.

Sokal, R. R. and Rohlf, F.J. (2013). Introduction to Biostatistics, $2^{\text {nd }}$ ed. Dover. NewYork, 1099-1121.

Sharifi, Y., Akbari, A., \& Soltan, D. (2011). Multiplex polymerase chain reaction (PCR) assay for simultaneous detection of shiga-like toxin (stx 1 and stx 2), intimin (eae) and invasive plasmid antigen $\mathrm{H}(\mathrm{ipaH})$ genes in diarrheagenic Escherichia coli. African Journal of Biotechnology, 10(9), 1522-1526.

Spano, L.C., da Cunha, K.F., Monfardini, M.V., Bergamaschi, R.D., Isabel, F., Affonso, C. (2017). High prevalence of diarrheagenic Escherichia coli carrying toxin-encoding genes isolated from children and adults in southeastern Brazil. $B M C$ Infect Dis 17, 773 (2017).

Sperandio, V., \& Pacheco, A. R. (2012). Shiga toxin in enterohemorrhagic $E$. coli: regulation and novel anti-virulence strategies. Frontiers in cellular and infection microbiology, 2, 81

Sudershan, R., Kumar, R. N., Kulkarni, B., Kashinath, L., Bhaskar, V., \& Polasa, K. (2014). E coli pathotypes and their antibiotic resistance in young children with diarrhea in Hyderabad, India. Int Journal Curr Microbiol App Sci, 3(9), 647-654.

Toma, C., Lu, Y., Higa, N., Nakasone, N., Chinen, I., Baschkier, A., Iwanaga, M. (2003). Multiplex PCR assay for identification of human diarrheagenic Escherichia coli. Journal of clinical microbiology, 41(6), 2669-2671.

Versalovic, J., Carroll, K., Funke, G., Jorgensen, J., Landry, M., Warnock, D. (2011). Manual of clinical microbiology, ASM Press. Washington, DC.

Weinstein, M., Patel, J., Bobenchik, A. (2017). Clinical and laboratory standards institute. Performance Standards for Antimicrobial Susceptibility Testing, 27th ed.; Clinical and Laboratory Standards Institute: Wayne, PA, USA, 296. 